\title{
Mitigation of Lost Circulation in Oil-Based Drilling Fluids Using Oil Absorbent Polymers
}

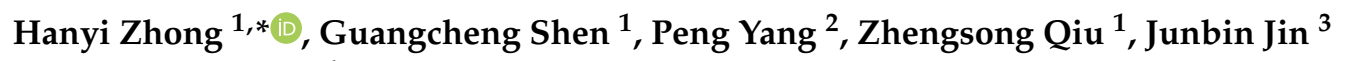 \\ and Xiaodong Xing 4 \\ 1 School of Petroleum Engineering, China University of Petroleum (East China), Qingdao 266580, China; \\ m18754272192@163.com (G.S.); qiuzs@upc.edu.cn (Z.Q.) \\ 2 GWDC Engineering Research Institute, Panjin 124010, China; yangpeng00625@163.com \\ 3 SINOPEC Research Institute of Petroleum Engineering, Beijing 100101, China; jinjb.sripe@sinopec.com \\ 4 China Petroleum Engineering \& Construction CORP, North China Company, Renqiu 062552, China; \\ xingxiaodong@cpeccnc.com \\ * Correspondence: zhonghanyi@126.com
}

Received: 26 September 2018; Accepted: 15 October 2018; Published: 18 October 2018

\begin{abstract}
In order to mitigate the loss circulation of oil-based drilling fluids (OBDFs), an oil-absorbent polymer (OAP) composed by methylmethacrylate (MMA), butyl acrylate (BA), and hexadecyl methacrylate (HMA) was synthesized by suspension polymerization and characterized by Fourier transform infrared spectroscopy (FT-IR), thermogravimetric analysis (TGA) and scanning electronic microscopy (SEM). The oil-absorptive capacity of OAP under different solvents was measured as the function of temperature and time. The effect of the OAP on the rheological and filtration properties of OBDFs was initially evaluated, and then the sealing property of OAP particles as lost circulation materials (LCMs) was examined by a high-temperature and high-pressure (HTHP) filtration test, a sand bed filtration test, a permeable plugging test, and a fracture sealing testing. The test results indicated that the addition of OAP had relatively little influence on the rheological properties of OBDF at content lower than $1.5 w / v \%$ but increased the fluid viscosity remarkably at content higher than $3 w / v \%$. It could reduce the HTHP filtration and improve the sealing capacity of OBDF significantly. In the sealing treatment, after addition into the OBDF, the OAP particles could absorb oil accompanied with volume enlargement, which led to the increase of the fluid viscosity and slowing down of the fluid loss speed. The swelled and deformable OAP particles could be squeezed into the micro-fractures with self-adoption and seal the loss channel. More important, fluid loss was dramatically reduced when OAP particles were combined with other conventional LCMs by a synergistic effect.
\end{abstract}

Keywords: lost circulation; oil-based drilling fluid; oil absorbent polymer; fracture sealing; combination

\section{Introduction}

In oil and gas drilling engineering, one of the frequently encountered problems is lost circulation, which is defined as the undesirable partial or complete loss of drilling fluid into formation voids during drilling, circulation, running casing, or cementing operations [1,2]. Once the total pressure exerted against the formation exceeds the formation breakdown pressure, lost circulation may be encountered at any depth. According to the statistics, the occurrence of lost circulation is present in approximately 20 to $25 \%$ of wells drilled around the world during drilling [3], and results in several troublesome problems such as excessive mud losses, non-productive time, stuck pipe, well kick, well blow-out and even abandonment of the wells [4-7]. Moreover, it has also been blamed for minimized production because the loss of fluid into a formation plugs the production zones and leads 
to decreased productivity [8,9]. More than 2 billion USD is spent to combat and mitigate this problem each year $[10,11]$. Lost circulation poses great challenges for the industry.

Lost circulation is generally observed in four kinds of formation including natural or induced fractured formations, vugular or cavernous formations, highly permeable formations, and unconsolidated formations [3]. Although the forms of loss like filtration loss, matrix seepage, and vugular loss may be of concern, losses through fracture propagation is the primary type and accounts for over $90 \%$ of the operator lost returns expenditures [7].

Over the past years, much effort has been made in an attempt to mitigate or stop lost circulation. A wide variety of lost circulation materials (LCMs) have been employed to form dense and integrated fracture sealing barriers [12]. The list of materials commercially available as LCMs is impressive [13,14]. Conventionally, these materials can be classified as fibrous, flaky, granular type, and mixtures of these [15]. For instance, particulate materials such as calcium carbonate and graphites, fibrous materials such as wood fiber, mineral fiber, and glass fiber; flake materials such as cellophane, mica and vermiculite; and granular materials such as perilite, nut shells and ground tires are widely used [16]. Meanwhile, other types of materials including cement, chemically activated cross-linked pilles, cross-linked cement, deformable-viscous-cohesive systems, nano-composite gel, gunk squeezes [17], polyurethane grouting, crosslinked gel, viscoelastic surfactant, nano-particles [18], reticulated foam [19], and shape memory polymers [20] have also attracted attention. These materials are generally added either to the drilling fluid or separately in the form of a sweep or a treating pill [21].

Because of the inherent advantages of high temperature stability, excellent lubricity, high wellbore stability, and tolerance to pollution and so on, invert emulsion drilling fluids (including oil-based drilling fluid (OBDF) and synthetic-based drilling fluid (SBDF)) are generally preferred when there are drilling demanding formations and complex conditions such as deep formation drilling, deep water drilling and gypsum and so on in comparison with water-based drilling fluids [22-24]. However, one potential drawback to the use of these fluids is the high cost associated with lost circulation [12]. On the one hand, the strong dependency of density on both temperature and pressure makes the invert-emulsion drilling fluid more compressible than the water-based drilling fluid, which subsequently results in a narrower drilling fluid density margin and easy occurrence of lost circulation $[25,26]$. On the other hand, for the pressure required to initiate hydraulic fracturing of the formation, there is no difference between water-based drilling fluid and invert emulsion drilling fluid; however, after the fractures are formed, there is a noticeable difference $[9,27,28]$. For water-based drilling fluid, a higher spurt fluid loss causes the almost instantaneous formation of a filter cake, and is then followed by a higher filtration loss, which results in the formation of thicker filter cakes, shielding the fracture tip from the maximum wellbore pressure and allowing bridges to develop that prevent further fracture propagation [26]. Meanwhile, the presence of filter cake can heal the fractures and lead to higher fracture re-opening pressures. Nevertheless, for invert emulsion drilling fluid, because of almost no dispersion of drilling cuttings, the filter cake is primarily composed of emulsion droplets and very thin and impermeable. Meanwhile, after wetting by the invert emulsion drilling fluid, the friction between LCMs and fracture plane decreases and cause the LCMs relatively difficult to bridging and forming effective sealing, which facilitate movement along these weak planes [29,30]. Therefore, once the fracture is initiated, a much smaller pressure is needed to propagate the fracture compared to water-based drilling fluid. This allows changes in wellbore pressures to be transmitted to the formation more readily, and further propagates the fracture [9,31]. Furthermore, although a variety of materials have been used as LCMs, materials specially designed to combat lost circulation in invert-emulsion drilling fluids are relatively fewer than that for water-based drilling fluids [25]. For solid particles, oil-wetting chemicals must typically be added to ensure the oil wet property when drilling with an OBDF [32]. Thereby, when using invert-emulsion drilling fluids, very few lost circulation remedies have been successful [33,34].

Water-absorbent resin is a kind of polymer with cross-linking structures which render the resin water-insoluble and capable of absorbing water of several to hundreds of times of its own weight. 
By deforming and being squeezed into the loss fractures with flexibility, the polymers can absorb water and fill in the fractures or pores. Due to the adsorption on the rock surface, it is easy for the polymers to stay in the loss channels and form a strong and pliable plug [35]. Because of the above advantages, water absorbent resin has been widely used in water-based drilling fluid as an effective LCM $[36,37]$. Behaving like water-absorbent resins, oil-absorbent resins having the cross-linked, three-dimensional, and hydrophobic networks that do not dissolve in oil are mainly used for absorbing oil in environmental pollution treatment [38]. Therefore, considering the similar properties between oil-absorbent resin and water-absorbent resin, the object of the current study is to probe the feasibility of oil absorbent resin in mitigating the loss of OBDFs.

\section{Materials and Methods}

\subsection{Materials}

Monomers including methylmethacrylate (MMA) (99\%), butyl acrylate (BA) (98\%), and hexadecyl methacrylate (HMA), cross-linking reagent $N, N^{\prime}$-Methylenebis (acrylamide) (MBA) (99\%) and initiator benzoyl peroxide (BPO) were purchased from Shanghai Aladdin Biochemical Technology Co. Ltd. (Shanghai, China) with analytical purity. Polyvinyl alcohol (PVA) using as dispersant agent, ethyl acetate (EAC) as porogen, and ethanol were bought from Sinopharm Chemical Reagent Co., Ltd. (Beijing, China) with analytical purity.

The low-toxicity mineral oil of No. 3 white oil used as the base oil was purchased from Shandong Taichang Petrochemical Technology Co., Ltd. (Qingdao, China). The organic clay with commercial name VG-Plus was provided by M-I Swaco Company of Schlumberger. Primary emulsifier BZ-OPE (amidoamine type) and secondary emulsifier BZ-OSE (fatty acid type) were provided by China National Petroleum Corporation (Tianjin, China). Rheological modifier SD-RM prepared from a reaction between polyacid and polyethene polyamine was provided by Shandong Shida Chuangxin Technology Co., Ltd. (Dongying, China). Barite used as weighting material was purchased from An County Huaxi mineral powder Co., Ltd. (Mianyang, China). Two types of conventional fluid loss additives including asphaltic additive and modified lignite used in OBDFs were provided by China National Petroleum Corporation and Shandong Shida Chuangxin Technology Co., Ltd. (Dongying, China), respectively. Lime ( $\mathrm{CaO}, \mathrm{pH}$ enhancer) and $\mathrm{CaCl}_{2}$ were bought from Sinopharm Chemical Reagent Co., Ltd. (Beijing, China). Calcium chloride was purchased from Sinopharm Chemical Reagent Co., Ltd. with analytical purity. The sized calcium carbonate (SCC) particles were provided by Jingmen Shun Zhan calcium Industry Co., Ltd. (Jingmen, China). The rubber (RUB) particles were obtained from Dujiangyan Huayi Rubber Co., Ltd. (Dujiangyan, China). The fibers (FIB) using as LCM were bought from Changzhou Tianyi engineering fiber Co., Ltd. (Changzhou, China). All the reagents were used as received without further purification.

\subsection{Synthesis and Characterization of Oil-Absorbent Polymer (OAP)}

The reaction was performed in $500 \mathrm{~mL}$, four-necks, round-bottom flasks equipped with a mechanical stirrer and heating device. Initially, $240 \mathrm{~mL}$ of PVA $(2 \mathrm{~g})$ solution was added into the flask and stirred for $30 \mathrm{~min}$ with water bath heated to $60^{\circ} \mathrm{C}$ for facilitation of dissolution. The system was charged with nitrogen gas and then sealed under nitrogen. Then, a mixture containing monomers of MMA (6 g), BA (16 g) and HMA (18 g), cross-linker MBA (0.3 g), initiator BPO $(0.4 \mathrm{~g})$ and porogen EAC $(5 \mathrm{~g})$ was added into the reactor within $10 \mathrm{~min}$. The polymerization reaction was performed at $80^{\circ} \mathrm{C}$ for $6 \mathrm{~h}$ under a stirring rate of $600 \mathrm{rpm}$. After reaction termination, the products were washed with absolute ethanol several times and then washed with hot deionized water $\left(60-70^{\circ} \mathrm{C}\right)$ several times. After washing, the sample was dried in vacuum drying oven (Qingdao Haitongda Special Instrument Co., Ltd., Qingdao, China) at $55^{\circ} \mathrm{C}$ for $24 \mathrm{~h}$ and finally the product of oil-absorbent polymer (OAP) was obtained as small beads. The particle size can be controlled by adjusting the stirring rate and the ratio of reaction monomers. 
The Fourier transform infrared (FT-IR) spectra were recorded by a Nicolet 6700 FT-IR spectrometer (Thermo Fisher Nicolet Corporation, Waltham, MA, USA), scanning from 4000 to $400 \mathrm{~cm}^{-1}$, with $4 \mathrm{~cm}^{-1}$ resolution in transmission. A TGA/DSC 1/1600 HT thermal analyzer from Mettler Toledo (Zurich, Switzerland) was used for thermogravimetric analysis (TGA) with a heating program from room temperature to $1000{ }^{\circ} \mathrm{C}$ at a heating rate of $10 \mathrm{~K} \mathrm{~min}^{-1}$ in nitrogen flow of $50 \mathrm{~mL} \mathrm{~min}{ }^{-1}$. The morphological features of the OAP were inspected with FEI Quanta FEG 250 field-emission scanning electron microscope (SEM, Hillsboro, OR, USA). The oil-adsorption capacity was conducted with the weighting method [39]. A quantity of $1 \mathrm{~g}$ of dried OAP samples was put into a filter bag and immersed in oil at a certain temperature. After a period of oil absorption, the filter bag with the sample was lifted from the oil and drained for $1 \mathrm{~min}$. Then the sample was immediately taken out, weighed and recorded. The oil absorbency was calculated as follows:

$$
\mathrm{R}=\frac{(W-1)}{1}
$$

where, $\mathrm{R}$ is the oil absorbency at a certain testing time, $\mathrm{g} / \mathrm{g} ; \mathrm{W}$ is the weight of OAP after oil adsorption for a certain testing time, $\mathrm{g}$.

\subsection{Preparation of Oil-Based Drilling Fluids (OBDFs)}

The mineral oil-based drilling fluids were prepared according to the experimental methods recommended in API RP 13B-2 [40]. The drilling fluid formula with oil to water ratio (OWR) of 90:10 is listed in Table 1. When the OWR of the fluid changed, the concentration of primary emulsifier and assistant emulsifier would be adjusted correspondingly to ensure the emulsion stability. The fluids were hot rolled in a rolling oven (Qingdao Haitongda Special Instrument Co., Ltd., Qingdao, China) at a certain desired temperature for $16 \mathrm{~h}$. After the dynamic aging, the fluids were cooled down to room temperature and agitated for $10 \mathrm{~min}$ at 10,000 rpm before it was analyzed.

Table 1. Base formula of oil-based drilling fluids (OBDF) with oil to water ratio (OWR) of 90:10.

\begin{tabular}{cccc}
\hline Component & Commercial Name & Content & Unit \\
\hline White oil & No. 3 & 360 & $\mathrm{~mL}$ \\
Organic clay & VG-Plus & 12 & $\mathrm{~g}$ \\
Primary emulsifier & BZ-OPE & 12 & $\mathrm{~g}$ \\
Assistant emulsifier & BZ-OSE & 12 & $\mathrm{~g}$ \\
Wetting agent & BZ-OWA & 8 & $\mathrm{~g}$ \\
$\mathrm{Rheological} \mathrm{modifier}_{\mathrm{CaCl}}$ solution $(25 \mathrm{wt} \%)$ & SD-RM & 4 & $\mathrm{~g}$ \\
CaO & & 40 & $\mathrm{~mL}$ \\
Barite & & 8 & $\mathrm{~g}$ \\
\hline
\end{tabular}

\subsection{Rheological Properties and Electrical Stability Measurement}

The rheological properties of the fluids were carried out at $50{ }^{\circ} \mathrm{C}$ according to the standard American Petroleum Institute Recommended Practice (API RP) 13B-2. The rheological parameters including apparent viscosity (AV), plastic viscosity (PV), yield point (YP), and gel strength of the OBDFs were measured using a model ZNN-D6 six-speed rotating viscometer (Qingdao Haitongda Special Instrument Co., Ltd., Qingdao, China). The AV, PV and YP were calculated from 300 and $600 \mathrm{rpm}$ readings by the following equations:

$$
\begin{aligned}
& \text { Apparent viscosity }(\mathrm{AV})=\Phi 600 / 2(\mathrm{mPa} \cdot \mathrm{s}) \\
& \text { Plastic viscosity }(\mathrm{PV})=\Phi 600-\Phi 300(\mathrm{mPa} \cdot \mathrm{s}) \\
& \text { Yield point }(\mathrm{YP})=0.48(\Phi 300-\mathrm{PV})(\mathrm{Pa})
\end{aligned}
$$


The $\mathrm{Gel}_{\text {in }}$ and $\mathrm{Gel}_{10 \mathrm{~min}}$ were recorded as the maximum dial reading at a fixed rate of $3 \mathrm{r} / \mathrm{min}$ after undisturbed for $10 \mathrm{~s}$ and $10 \mathrm{~min}$, respectively [41]. The electrical stability (ES) of the OBDFs was measured using the electrical stability tester (Qingdao Shande Petroleum Apparatus Co., Ltd., Qingdao, China).

\subsection{Filtration Properties Measurement}

Different filter presses are used to determine the filtration property of drilling fluids. The API filtrate volume of OBDFs before and after hot rolling was tested by a ZNZ-D3-type medium-pressure filtration apparatus (Qingdao Haitongda Special Instrument Co., Ltd., Qingdao, China). The volume of filtration was collected through filter paper as filtration medium under a fixed pressure of $0.7 \mathrm{MPa}$ for $30 \mathrm{~min}$ as recommended with API standard.

In most situations, drilling fluid filtrate into the formation in the drilling is a dynamic process; therefore, the high-temperature and high-pressure (HTHP) dynamic fluid loss was measured with a HTHP dynamic filter press (Figure 1) (Qingdao Haitongda Special Instruments Co., Ltd.) at a stirring speed of $100 \mathrm{rpm}$. The tests were run for $30 \mathrm{~min}$ at a differential pressure of $3.5 \mathrm{MPa}$ and $150{ }^{\circ} \mathrm{C}$. The filtrate was collected with filter paper as filter medium.

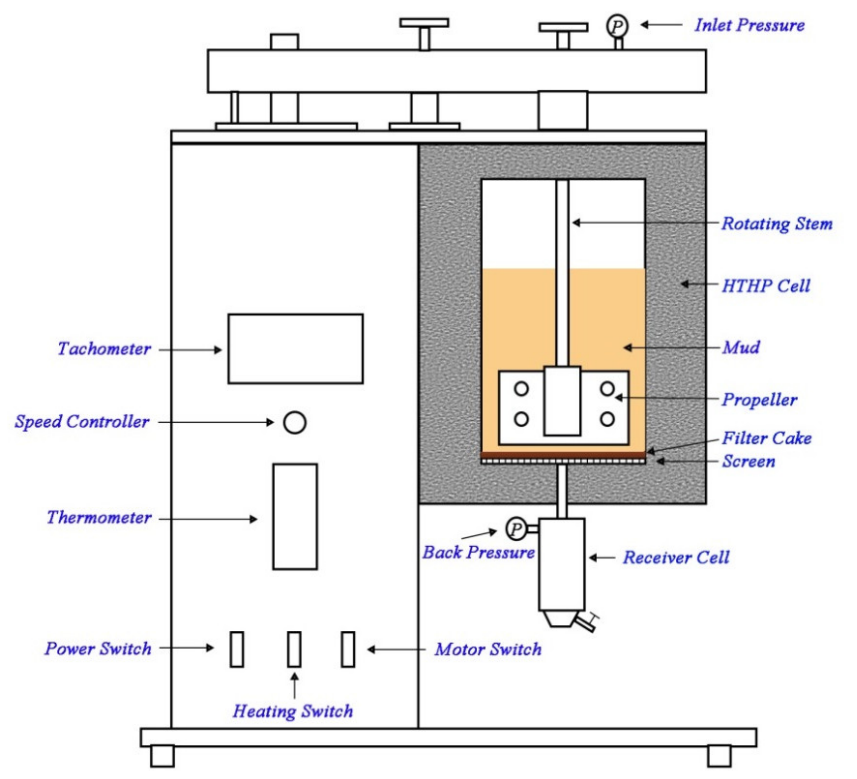

Figure 1. Scheme of high-temperature and high-pressure (HTHP) dynamic filtration cell.

When the circulation of drilling fluid stops because of accidents or downhole operations, a static filtration occurs. To simulate the static filtration behavior of drilling fluid, the HTHP static fluid loss was conducted via the HTHP filter apparatus (GGS71-B, Qingdao Haitongda Special Instruments Co., Ltd.) under the condition of a certain temperature and 3.5 MPa pressure difference for a period of $30 \mathrm{~min}$. The volume of filtration and the thickness of the filter cake were recorded.

\subsection{Properties of Sealing}

To evaluate the sealing performance of OAP, four distinctive tests including HTHP filtration (including both static and dynamic filtration) using API filter paper as the filtration medium to simulate the permeable formation [42]; a permeability plugging test using ceramic disk as filtration medium to determine the ability of particles in the drilling fluid to bridge pores [43]; a sand bed filtration test using a sand bed as filtration medium to simulate an unconsolidated formation; and a fracture sealing test using wedged and slotted stainless steel as filtration medium to simulate a fractured formation were carried out $[44,45]$. 
The test procedure of the sand bed filtration test and permeability plugging test refer to Zhong et al. [46]. The sand particles used for sand bed filtration test have the particle size ranging from $380 \mu \mathrm{m}$ to $830 \mu \mathrm{m}$. The sand disk using for permeability plugging test was calibrated to $10 \mathrm{D}$.

In order to evaluate the fracture plugging capacity of LCMs, a fracture sealing testing apparatus (Figure 2, Instrument Factory of Petroleum University, Dongying, China) with tapered and slotted stainless steel discs (Figure 3) that simulate natural/induced fractures was adopted. Firstly, tapered slots were placed before the output valve. Then, fluids containing LCMs were forced to flow at a constant stirring rate of $100 \mathrm{rpm}$ through the discs with a gradual increase of pressure. The applied pressure was initially set to be $1.0 \mathrm{MPa}$ and kept stable for $10 \mathrm{~min}$. If the LCMs effectively sealed the fracture and the pressure declined within $5 \%$, the pressure was continuously increased and the volume of fluid loss was recorded. Once a continuous leakage of fluid occurred, it was asserted that the LCMs had reached the maximum pressure bearing capacity and the test was ceased. Treatments with lower fluid loss values correspond to effectiveness of mitigating the loss. However, because of the limitation that the maximum applied pressure is $8.0 \mathrm{MPa}$ for the equipment, the maximum pressure at which the formed seal breaks and fluid loss resumes was not measured.

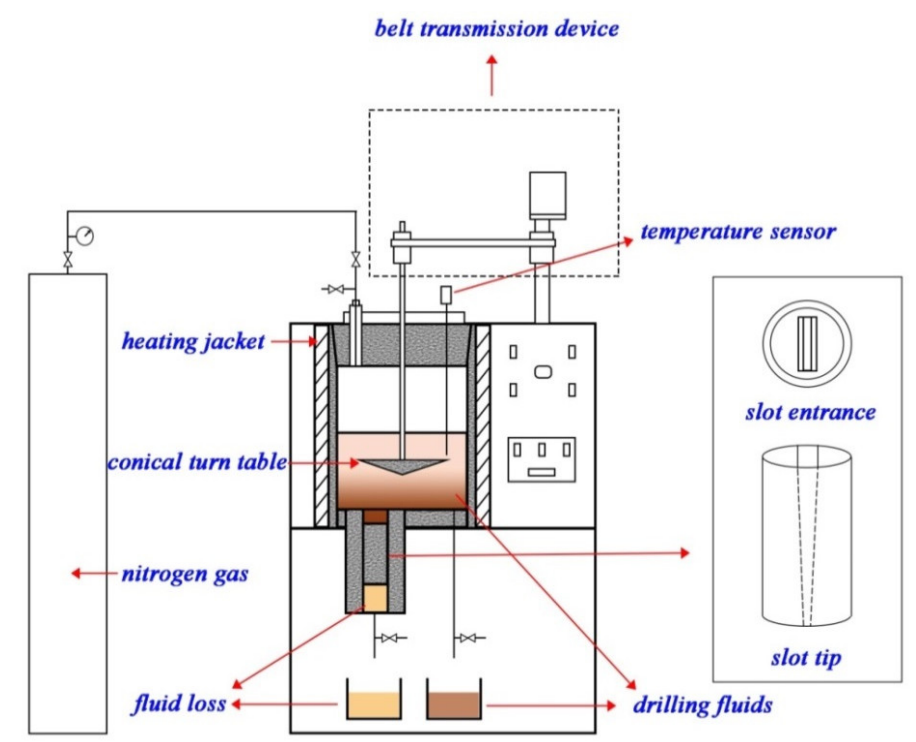

Figure 2. Fracture pressure bearing capacity test apparatus.
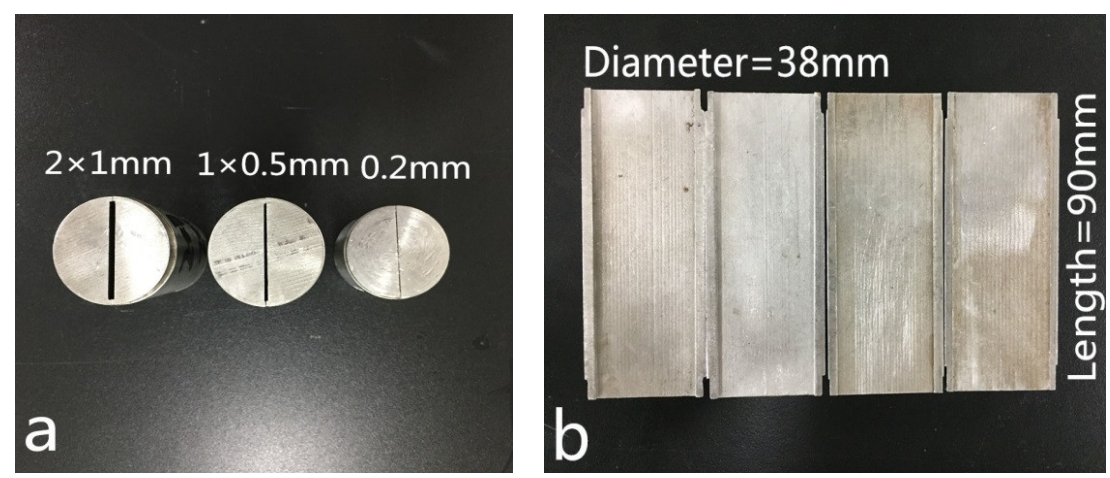

Figure 3. Tapered slots with various fracture sizes for fracture sealing testing. Note: (a) Size dimensions; (b) fracture profile. 


\section{Results}

\subsection{Characterization of $O A P$}

\subsubsection{Fourier Transform Infrared (FT-IR) Spectra}

A possible chemical reaction mechanism for OAP is depicted in Figure 4. The FT-IR spectrum of the copolymer prepared by suspension polymerization is shown in Figure 5. The characteristic absorption bands that appeared at 2920 and $2850 \mathrm{~cm}^{-1}$ were assigned to the asymmetric and symmetric stretching vibrations of $\mathrm{C}-\mathrm{H}$, respectively. The bands at $1730 \mathrm{~cm}^{-1}$ were attributed to $\mathrm{C}=\mathrm{O}$ stretching vibration. The bands at 1470 and $1380 \mathrm{~cm}^{-1}$ corresponded to the $\mathrm{C}-\mathrm{H}$ asymmetric and symmetric bending vibration. The bands at 1240 and $1160 \mathrm{~cm}^{-1}$ were the $\mathrm{C}-\mathrm{O}-\mathrm{C}$ asymmetric stretching vibration and symmetric stretching vibration, respectively. The band at $1030 \mathrm{~cm}^{-1}$ was assigned to the $\mathrm{C}-\mathrm{N}$ stretching vibration. The bands at 723 and $640 \mathrm{~cm}^{-1}$ were the out of plane bending vibration of $\mathrm{N}-\mathrm{H}$ (amide $\mathrm{V}$ ) and $\mathrm{C}=\mathrm{O}$ (amide VI), respectively. The disappearance of $\mathrm{C}=\mathrm{C}$ bands usually at $1620-1680 \mathrm{~cm}^{-1}$ indicated the thorough reaction of the monomers.

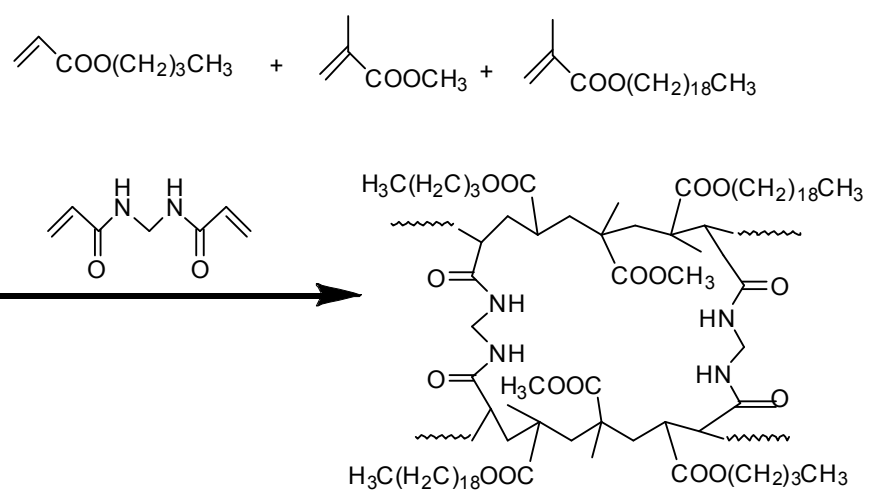

Figure 4. Possible chemical reaction mechanism for oil-absorbent polymer (OAP).

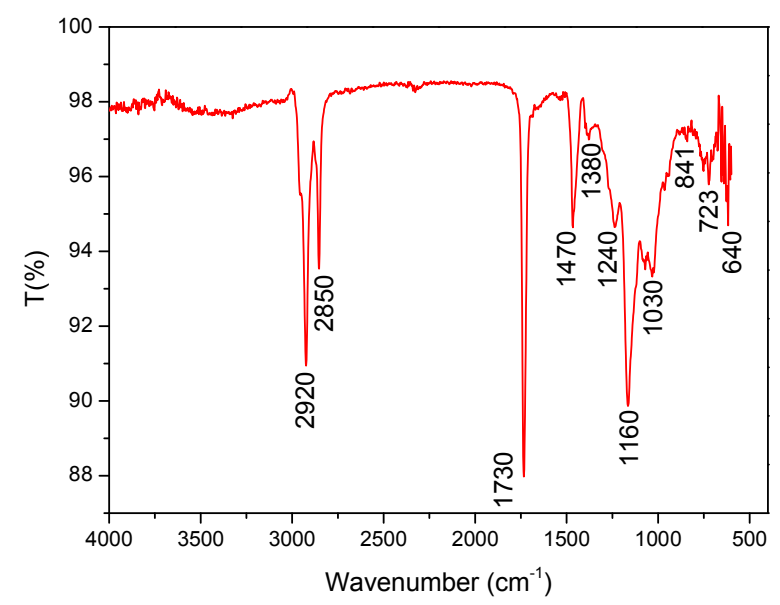

Figure 5. Fourier transform infrared (FT-IR) spectrum of oil-absorbent polymer (OAP).

\subsubsection{Thermogravimetric Analysis (TGA)}

The thermal stability is of vital importance for OAP because it has to experience downhole high temperature conditions. Figure 6 presents the resolution of weight percent of OAP sample with the change of temperature and the first derivative thermogravimetric curve. It could be seen that before $100{ }^{\circ} \mathrm{C}$ little weight loss was observed. The copolymer began to degrade rapidly when the temperature reached $300{ }^{\circ} \mathrm{C}$. The sample weight loss is about $50.12 \%$ at $386{ }^{\circ} \mathrm{C}$. The maximum pyrolysis rate occurred at about $392{ }^{\circ} \mathrm{C}$. When the temperature reached $436{ }^{\circ} \mathrm{C}$, the sample came to the total 
pyrolysis. The results indicated that OAP had a good thermal stability and could be used in high temperature environments.

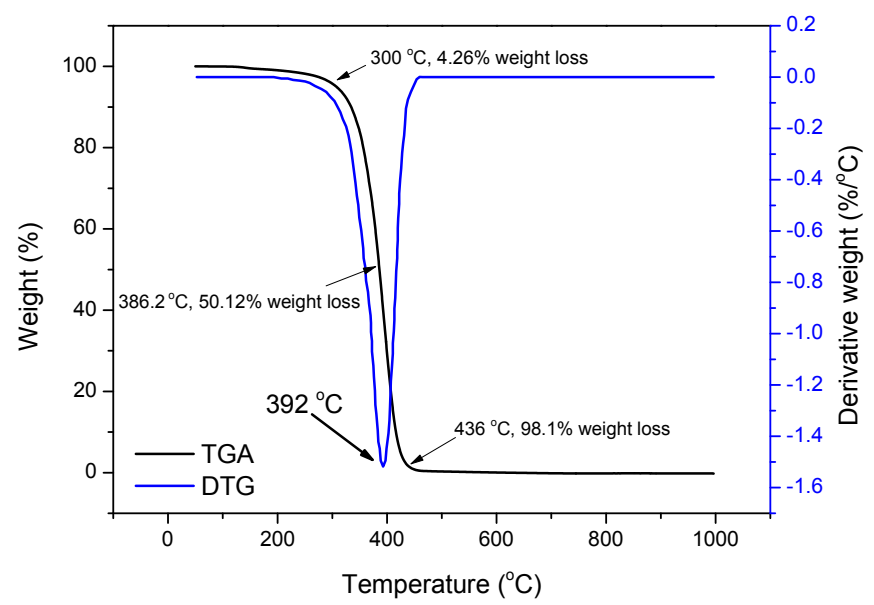

Figure 6. Thermogravimetric analysis (TGA) and Derivative thermogravimetric analysis (DTG ) curves of OAP.

\subsubsection{Scanning Electron Microscopy (SEM)}

In order to observe the microstructure of OAP, SEM was used to inspect the cross section and surface morphologies of OAP samples, as depicted in Figure 7. From Figure 7a, aggregated micrometer-sized spheres were clearly observed. It is worth mentioning that many small pores were randomly distributed in the samples. There pores support the favorable space in the polymer network. The three-dimensional network structure and micro-pores with proper size and quantity was beneficial for the oil molecules to enter into the internal space; however, it is not easy for the oil molecules to exude from the three-dimensional crosslinked resin, like a sponge [47].
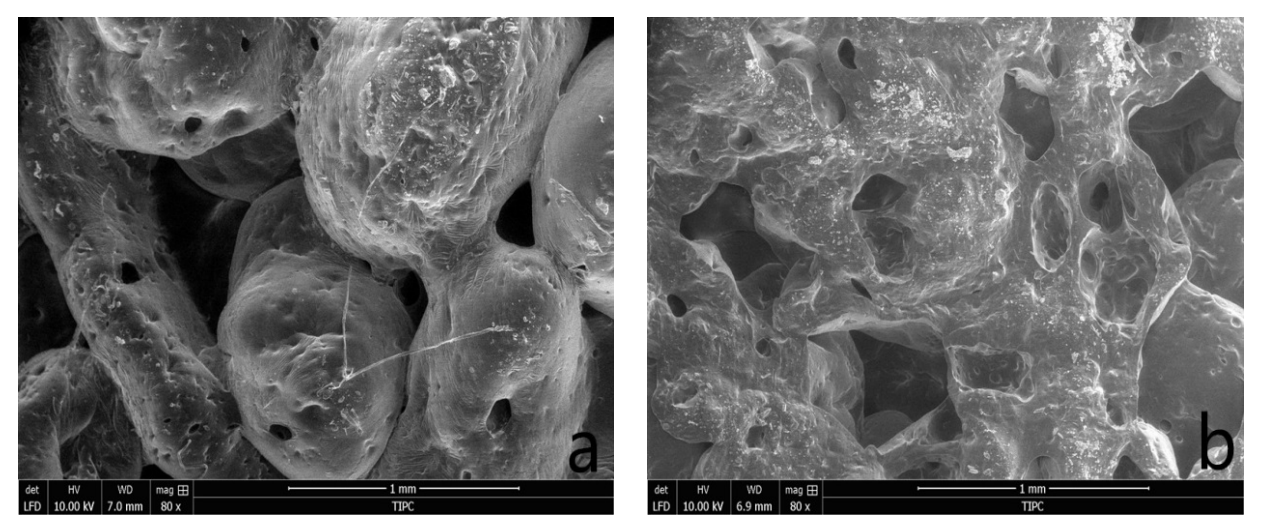

Figure 7. Scanning electron microscope (SEM) microphotographs of OAP. Note: (a) Surface; (b) cross section.

\subsection{Oil-Adsorptive Capacity}

The evolution of oil adsorptive rate which is calculated with Equation (1) with time is depicted in Figure 8. As can be seen from Figure 8, for both No. 3 white oil and diesel oil, a quick adsorption rate was observed for the initial testing interval of $20 \mathrm{~h}$, followed by a slightly increased adsorptive rate, and it finally reached saturated adsorption. After testing for $72 \mathrm{~h}$, the white oil absorbency was 8.3, 9.9, $11.4 \mathrm{~g} / \mathrm{g}$ for testing temperature of room temperature, $90^{\circ} \mathrm{C}$ and $120^{\circ} \mathrm{C}$, and the diesel oil absorbency was $6.7,7.6,9.0 \mathrm{~g} / \mathrm{g}$ accordingly. Based on the field experience, the saturation adsorption time of water absorbent resin higher than $5 \mathrm{~h}$ would be sufficient for the resin to be injected into the 
downhole and fulfil its role [48], therefore for OAP, it would not become adsorption saturation before reaching the desired thief zone, which is advantageous for downhole application. OAP particles would still absorb oil when entering the loss fractures and prevent fluid loss. Meanwhile, the oil-adsorptive rate increased with the increasing testing temperatures, implying that OAP would adsorb a larger amount of oil in the downhole environment. Moreover, the saturation adsorptive amount of white oil was higher than that of diesel oil, demonstrating that OAP may be more effective in white oil-based drilling fluid.
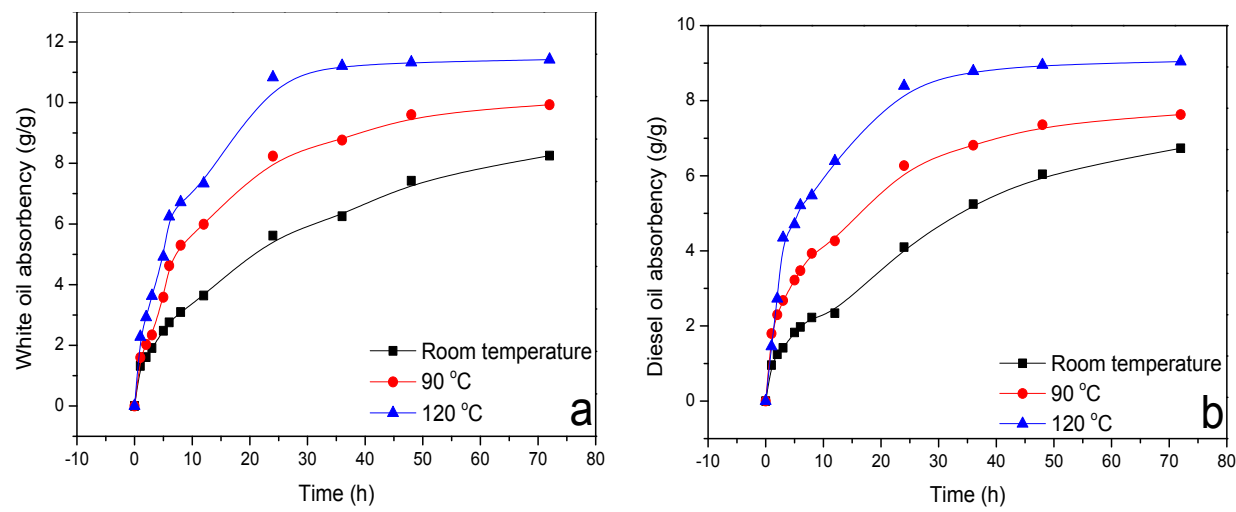

Figure 8. Evolution of oil adsorptive rate with time under various temperatures. Note: (a) white oil; (b) diesel oil.

Optical microscope photographs of OAP particles before and after white oil adsorption are displayed in Figure 9. An explicit distinction was observed between original OAP and swollen OAP. As shown in Figure 9a, before oil adsorption, a large amount of spherical particles with some cavities were accumulated together and formed an irregular surface, whereas, after reaching saturated adsorption, the small particles expanded significantly and filled in the gap space between the adjacent particles, forming a smooth surface.
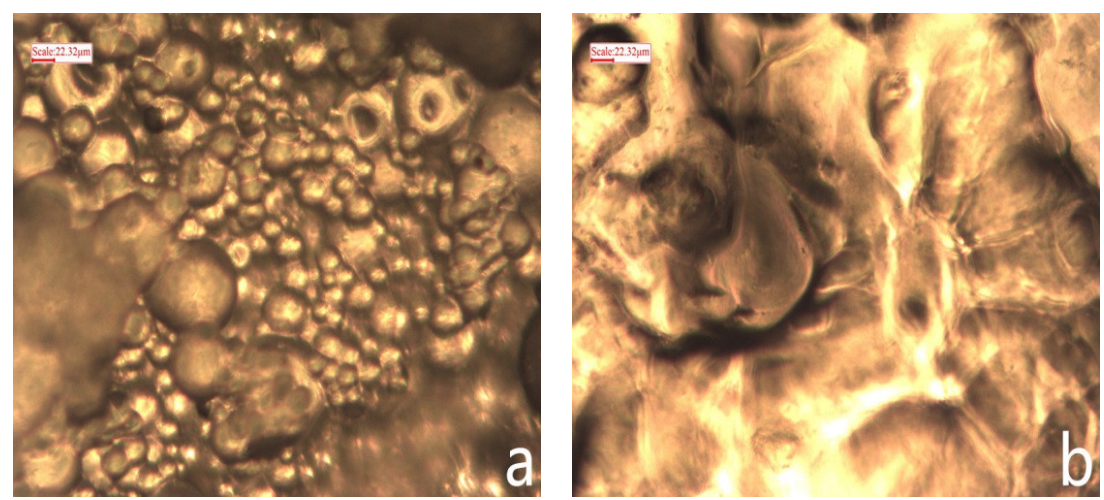

Figure 9. Microphotogram of OAP particles before (a) and after (b) No. 3 white oil adsorption.

\subsection{Influence of OAP on the Properties of OBDFs}

The effect of OAP particles (particle size of 80-100 mesh) on the properties of OBDFs was investigated firstly. OAP with various contents was added into the OBDFs. The fluid was hot-rolled at $120{ }^{\circ} \mathrm{C}$ for $16 \mathrm{~h}$. The properties of the fluids before and after hot rolling are given in Table 2. Before hot rolling, the addition of OAP had little influence on the rheological properties of the OBDFs, scuh that AV (calculated with Equation (2)), PV (calculated with Equation (3)), YP (calculated with Equation (4)) and Gel changed slightly with the increase of OAP content; however, after hot rolling, the rheological parameters including AV, PV, YP and Gel strength all increased gradually initially when the OAP content was lower than $1.5 w / v \%$, and showed a significant increase at content of 
$3 w / v \%$. In terms of filtration control, as shown in Table 2, the API fluid loss decreased gradually with the increasing content of OAP for both before and after hot rolling. Also as depicted in Figures 10 and 11 , for the HTHP static filtration test conducted under $120^{\circ} \mathrm{C}$ and $3.5 \mathrm{MPa}$ after hot rolling, both of the HTHP static fluid loss volume and filter cake thickness decreased with the increased content of OAP, which was reduced by $74 \%$ and $24 \%$, respectively, when $3 w / v \%$ OAP was added, indicating that OAP could effectively reduce the filtration loss and improve the filter cake quality. In regard to the electrical stability (ES) of the drilling fluid, which is one of the vital properties of an oil-based drilling fluid, this shows the voltage of the current flowing in the fluid and represents the emulsion stability of the fluid. The emulsion-breaking voltage decreased generally with the increasing content of OAP.

Table 2. Effect of OAP on the properties of oil-based drilling fluid (OBDF) base formula.

\begin{tabular}{|c|c|c|c|c|c|c|c|}
\hline Content $(w / v \%)$ & $\begin{array}{l}\text { Testing } \\
\text { Condition }\end{array}$ & $\begin{array}{c}\text { AV } \\
(\mathrm{mPa} \cdot \mathrm{s})\end{array}$ & $\begin{array}{c}\text { PV } \\
(\mathrm{mPa} \cdot \mathrm{s})\end{array}$ & $\begin{array}{l}\text { YP } \\
(\mathbf{P a})\end{array}$ & $\begin{array}{c}\text { Gel } \\
(\mathrm{Pa} / \mathrm{Pa})\end{array}$ & $\begin{array}{l}\mathrm{FL}_{\text {API }} \\
(\mathrm{mL})\end{array}$ & $\begin{array}{c}\text { ES } \\
\text { (Volt) }\end{array}$ \\
\hline \multirow[b]{2}{*}{0} & BHR & 11 & 9 & 1.9 & $1.5 / 2$ & 7 & \multirow[b]{2}{*}{2047} \\
\hline & AHR & 12 & 9 & 2.9 & $2.0 / 3$ & 7.4 & \\
\hline \multirow{2}{*}{0.5} & BHR & 12.5 & 9 & 3.4 & $1.0 / 1.0$ & 5.6 & \multirow{2}{*}{2047} \\
\hline & AHR & 18 & 14 & 3.8 & $1.0 / 1.5$ & 5.3 & \\
\hline \multirow{2}{*}{1} & BHR & 15 & 12 & 2.9 & $1.0 / 1.5$ & 4.8 & \multirow{2}{*}{1980} \\
\hline & AHR & 28 & 18 & 9.6 & $1.5 / 2$ & 3.1 & \\
\hline \multirow{2}{*}{1.5} & BHR & 11.5 & 10 & 1.4 & $1.5 / 2$ & 5.6 & \multirow{2}{*}{1562} \\
\hline & AHR & 31 & 18 & 12.5 & $3.5 / 4.5$ & 2.4 & \\
\hline \multirow{2}{*}{3} & BHR & 17 & 10 & 6.7 & $1.5 / 1.75$ & 2.2 & \multirow{2}{*}{1345} \\
\hline & AHR & 98.5 & 65 & 32.2 & $8.0 / 9$ & 1.2 & \\
\hline
\end{tabular}

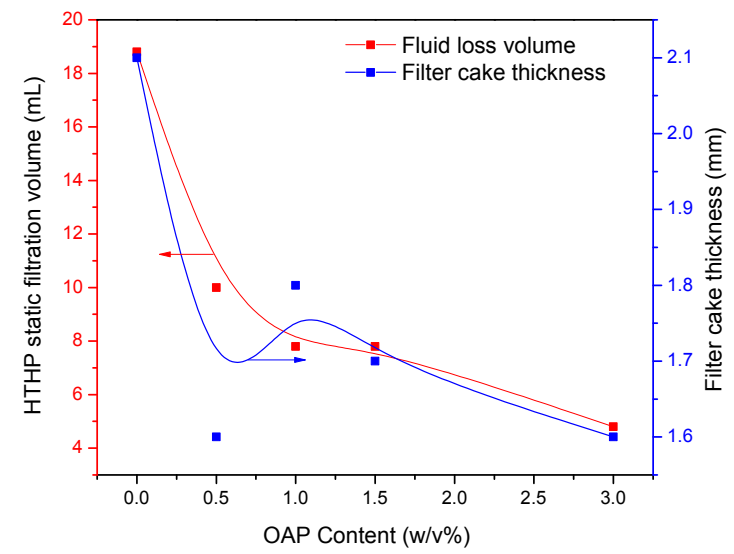

Figure 10. Variation of HTHP static filtration volume and filter cake thickness as a function of OAP content.
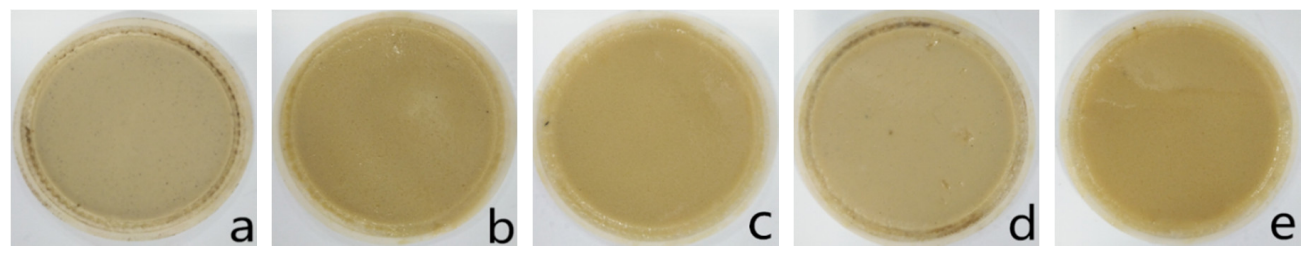

Figure 11. Photograph of HTHP filtration cakes with varying OAP contents. Note: (a) control sample; (b) $0.5 w / v \%$ OAP; (c) $1.0 w / v \%$ OAP; (d) $1.5 w / v \%$ OAP; (e) $3.0 w / v \%$ OAP.

The impact of OAP particles on the properties of OBDF could be explained by the fact that, when OAP particles were added into the fluid initially, it began to adsorb oil, but the adsorptive content was relatively low. After hot rolling at high temperatures for a certain time, a large amount 
of oil was adsorbed by OAP, resulting in the decreased amount of free oil in the system. Meanwhile the swelled volume of OAP particles increased the friction of the fluid. The decreased content of free base oil and increased friction in the fluid contributed to the viscosity buildup, lower fluid loss and reduction of emulsion stability. Furthermore, the expansive OAP particles participated in forming the filter cake, which was also favorable for reducing filtration.

\subsection{Sealing Properties of $O A P$}

\subsubsection{High-Temperature and High-Pressure Filtration Test}

Two commercially available fluid loss additives including asphaltic additive and modified lignite were used as reference to compare the versatility of OAP. The fluid loss additives with $1 w / v \%$ contents were added into the base formula of the OBDF and hot rolled at $120^{\circ} \mathrm{C}$ for $16 \mathrm{~h}$, and then the HTHP filtration tests were performed. As shown in Figure 12, for the HTHP static filtration test, the fluid loss volume was 32.4, 13.2, 20.4 and $23.6 \mathrm{~mL}$ for the base fluid, fluid containing OAP, modified lignite and asphaltic additives, respectively, showing the capacity of decreasing HTHP static filtration with the sequence of OAP > modified lignite $>$ asphaltic additives. For the HTHP dynamic filtration test, the fluid loss volume increased to 115.2, 52.0, 97.6 and $62.4 \mathrm{~mL}$ for the four fluids, showing the ability of decreasing HTHP dynamic filtration following the order of OAP $>$ asphaltic additive $>$ modified lignite. The significant increase of fluid loss compared with that of static filtration lies in the fact that filter cake was more difficult to form under a dynamic shear condition [49]. Overall, the three candidate additives all exhibited effective performance in HTHP filtration control.
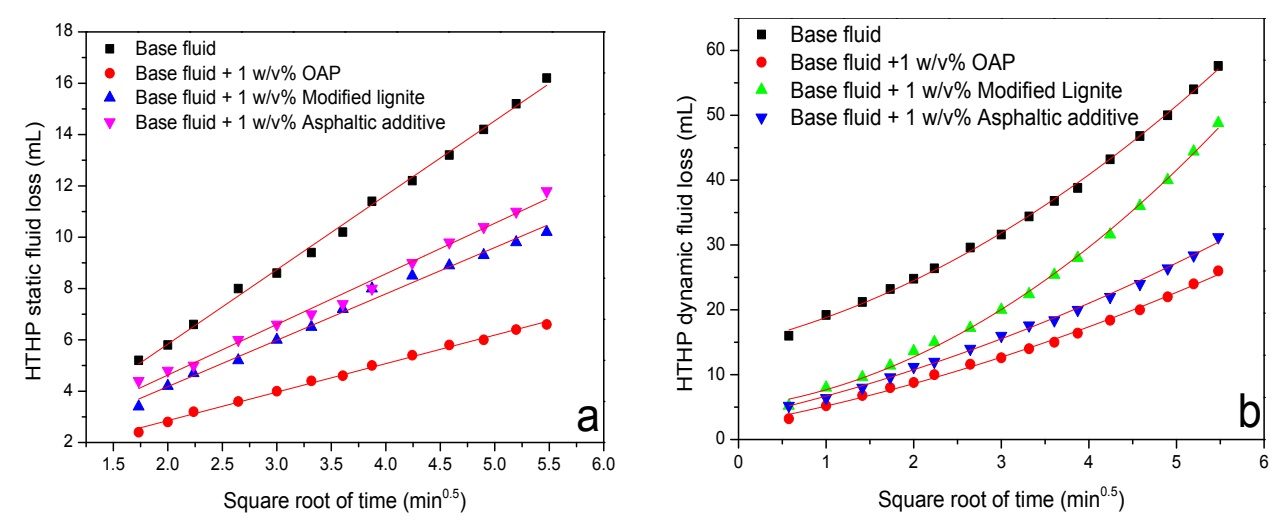

Figure 12. HTHP static fluid loss (a) and dynamic fluid loss (b) versus square root of time.

The cumulative fluid loss volume of both HTHP static filtration test and HTHP dynamic filtration test as a function of square root of time was analyzed with different mathematic models. For HTHP static filtration, a typical model recommended by API standard was given as follows [50],

$$
\mathrm{V}=\mathrm{V}_{\mathrm{sp}}+\mathrm{m} \sqrt{\mathrm{t}}
$$

where $\mathrm{V}_{\mathrm{sp}}$ and $\mathrm{m}$ are the intercept and slope of the line, representing the spurt loss and filtration rate, respectively.

While for HTHP dynamic filtration test, another model describing the filtration in a dynamic test consisting of three separate steps: (1) spurt loss, (2) filter-cake deposition (square-root-of-time dependence), and (3) limitation of cake buildup by erosion (linear time dependence), was proposed by Roodhart [51] as follows,

$$
\mathrm{V}=\mathrm{V}_{\mathrm{sp}}+\mathrm{m} \sqrt{\mathrm{t}}+\mathrm{Bt}
$$

where $\mathrm{V}_{\mathrm{sp}}$ indicates the spurt loss, the constants $\mathrm{m}$ and $\mathrm{B}$ represent the static and dynamic filtration components. 
According to the proposed models (Equations (5) and (6)), the HTHP filtration test data were fitted and given in Table 3. It could be seen that the two models appeared to fit well as the value of $R^{2}$ all approached to 1 . With regard to the HTHP static filtration test, the addition of fluid loss reducers caused the increase of spurt loss, but lowered the filtration rates. The fluid in the presence of OAP generated the lowest filtration rate. For the HTHP dynamic filtration test, all the filtration components including spurt loss, static filtrate rate, and dynamic filtration rate decreased obviously after addition of the fluid loss reducers. The difference of filtrate rate between static and dynamic filtration was not clear, whereas, it was obvious that OAP was capable of reducing HTHP fluid loss more effectively than modified lignite and asphaltic additive under both static and dynamic conditions.

Table 3. HTHP static filtration and dynamic filtration test results for OBDFs containing various fluid loss additives.

\begin{tabular}{cccccccc}
\hline \multirow{2}{*}{ Drilling Fluid Formula } & \multicolumn{3}{c}{ HTHP Static Filtration } & \multicolumn{4}{c}{ HTHP Dynamic Filtration } \\
\cline { 2 - 8 } & $\mathbf{V}_{\mathbf{s p}}$ & $\mathbf{m}$ & $\mathbf{R}^{\mathbf{2}}$ & $\mathbf{V}_{\mathbf{s p}}$ & $\mathbf{m}$ & $\mathbf{B}$ & $\mathbf{R}^{\mathbf{2}}$ \\
\hline Base fluid & 0.1075 & 2.8814 & 0.9982 & 14.771 & 3.2301 & 0.8218 & 0.9989 \\
Base fluid $+1 w / v \%$ OAP & 0.4689 & 1.1507 & 0.9960 & 2.3177 & 2.5393 & 0.3072 & 0.9971 \\
$\quad$ Base fluid $+1 w / v \%$ & 0.3295 & 1.8622 & 0.9942 & 4.9221 & 1.6198 & 1.1411 & 0.9984 \\
$\quad \begin{array}{l}\text { Modified lignite } \\
\text { Base fluid + 1 } w / v \%\end{array}$ & 0.7577 & 1.9535 & 0.9955 & 3.3494 & 2.9944 & 0.3557 & 0.9977 \\
$\quad$ Asphaltic additive & & & & & & & \\
\hline
\end{tabular}

\subsubsection{Permeability Plugging Test}

The results of the permeability plugging tests of OBDFs with and without fluid loss reducers are shown in Figure 13 and Table 4. The total loss of control sample was as high as $47.6 \mathrm{~mL}$, indicating that base fluid was not able to plug the micro-pores of disks. However, an obvious decrease of total loss was observed after the addition of $1 w / v \%$ fluid loss reducers. Furthermore, the static filtration rate decreased from $6.57 \mathrm{~mL} / \mathrm{min}^{1 / 2}$ to $0.95,2.26,3.43 \mathrm{~mL} / \mathrm{min}^{1 / 2}$ after incorporation of OAP, modified lignite, and asphalt additive, respectively. Because of the elastic and deformable properties, OAP particles could be easily squeezed into the micro-pores. After entering the micro-pores, the particles continued to absorb oil and swell to saturation state. The enlarged volume could effectively fill in the micro-pores and lead to the decrease of fluid loss.

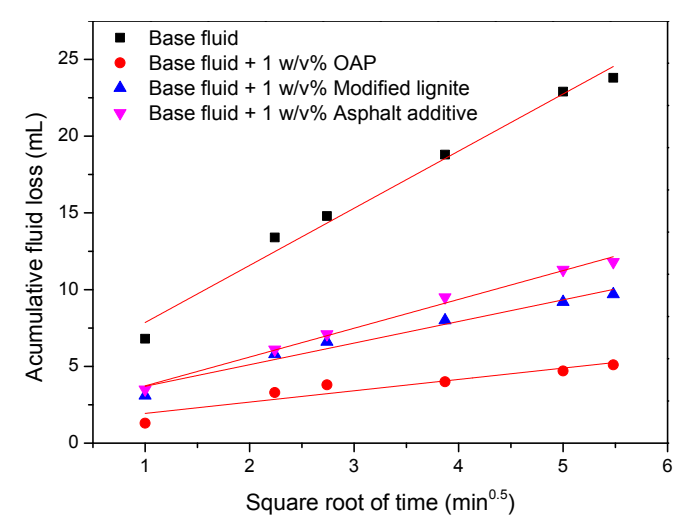

Figure 13. Fluid losses versus the square root of minutes for the permeability plugging test. 
Table 4. Effect of various sealing agents on the fluid loss of OBDFs obtained via permeability plugging test.

\begin{tabular}{cccc}
\hline Testing Sample & $\begin{array}{c}\text { Total Fluid } \\
\text { Loss }(\mathbf{m L})\end{array}$ & $\begin{array}{c}\text { Spurt Loss } \\
(\mathbf{m L})\end{array}$ & $\begin{array}{c}\text { Static Filtration Rate } \\
\left(\mathbf{m L} / \mathbf{m i n}^{\mathbf{1} / \mathbf{2}}\right)\end{array}$ \\
\hline Base fluid & 47.6 & 11.6 & 6.57 \\
Base fluid $+1 w / v \%$ OAP & 10.2 & 5 & 0.95 \\
Base fluid $+1 w / v \%$ Modified lignite & 19.4 & 7 & 2.26 \\
Base fluid $+1 w / v \%$ Asphalt additive & 23.6 & 4.8 & 3.43 \\
\hline
\end{tabular}

\subsubsection{Sand Bed Filtration Test}

The sand bed filtration test was designed to more realistically evaluate the tendency of a fluid to invade a permeable and unconsolidated formation [42]. As shown in Figure 14 and Table 5, when there was no sealing agent in the control sample, the base fluid invaded the sand bed readily and rapidly, and the total invasion depth reached about $7.2 \mathrm{~cm}$ after the test. After addition of sealing agents, the invasion depth decreased to a different extent. Compared with modified lignite and asphalt additive, OAP exhibited a better sealing performance. In the testing process, there was a small amount of initial invasion, followed by the rapid formation of a dense and extremely low permeability seal in just a few seconds. The fluid invasion ceased with an invasion depth of only $1.5 \mathrm{~cm}$, which was the shortest invasion depth observed in contrast with other two products. This rapid shutoff of invasion was crucial in achieving the excellent results seen in the field.
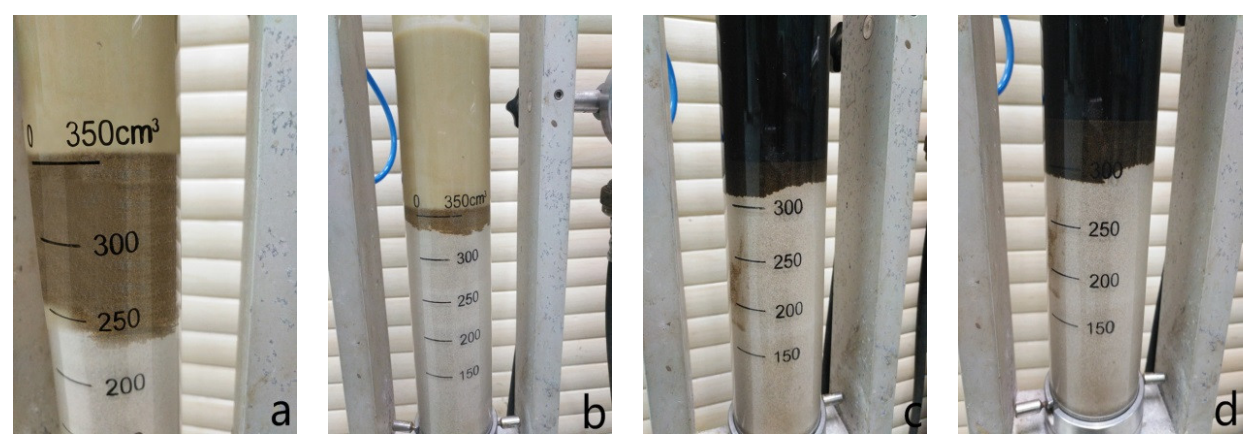

Figure 14. Comparison of the sand bed invasion depths for various fluid loss additives. Note: (a) control sample; (b) OAP; (c) asphaltic additive; (d) modified lignite.

Table 5. Comparison of invasion depths of various OBDF formulas for a sand bed filtration test.

\begin{tabular}{cc}
\hline Testing Sample & Average Invasion Depth $\mathbf{( c m )}$ \\
\hline Base fluid & 7.2 \\
Base fluid $+1 w / v \%$ OAP & 1.5 \\
Base fluid $+1 w / v \%$ Modified lignite & 2.2 \\
Base fluid $+1 w / v \%$ Asphaltic additive & 2 \\
\hline
\end{tabular}

\subsubsection{Fracture Sealing Test}

(1) The sealing capacity of OAP in OBDF with a $0.2 \mathrm{~mm}$ width slot.

Firstly, the fracture sealing ability of OAP was evaluated by a $0.2 \mathrm{~mm}$ width slot to simulate light losses. OBDF with OWR of 80:20 containing $1 w / v \%$ OAP with size of 80-100 mesh was poured into the cell. When the pressure increased to $1.0 \mathrm{MPa}$, almost all of fluid was lost, indicating sealing failure. After the experiment, the fracture was taken out. As shown in Figure 15, the swollen OAP particles had been forced into the fracture and were distributed along the fracture plane. Unlike rigid materials with high strength, OAP particles exhibited low compressive strength after oil adsorption, which could 
not form effective sealing alone. However, taking other materials such as SCC particles and sized RUB particles in combination, this relatively narrow fracture was easy to seal.

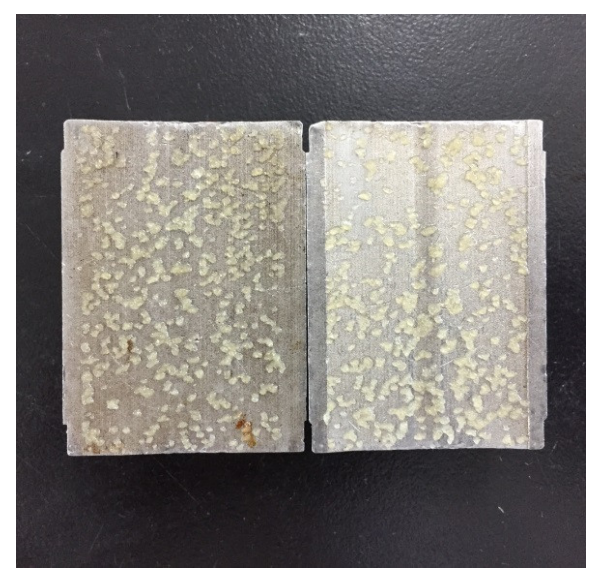

Figure 15. Performance of OAP to control the lost circulation in OBDFs (0.2 mm slot).

(2) The sealing capacity of LCMs in a $1 \times 0.5 \mathrm{~mm}$ width slot.

This fracture was selected to model light to medium losses. Because OAP individually could not effectively seal small fractures, to deal with this kind of loss it is widely accepted that combinations of LCMs are much more effective compared to just one type of LCM when curing lost circulation. The LCM's type, concentration, particle size distribution and fracture width are the vital factors for effective sealing [52]. Based on general experience, rigid particles like calcium carbonate, deformable particles like rubber, and fibers were used in combination to improve the sealing capacity in this study. The particle size classification of LCMs is presented in Table 6. According to effective bridging theory [53] and numerous laboratory experiments, an acceptable LCM formula No. 1 aimed for the $1 \times 0.5 \mathrm{~mm}$ tapered slot was established as a control sample and shown in Table 7 .

Table 6. Classification of lost circulation materials' (LCM) particle sizes.

\begin{tabular}{cccccc}
\hline Number & $\mathbf{0}$ & I & II & III & IV \\
\hline Mesh & $6 \sim 10$ & $10 \sim 20$ & $20 \sim 40$ & $40 \sim 80$ & $>80$ \\
Particle size $/ \mathrm{mm}$ & $3.2 \sim 2.0$ & $2.0 \sim 0.9$ & $0.9 \sim 0.45$ & $0.45 \sim 0.2$ & $<0.2$ \\
\hline
\end{tabular}

Table 7. LCM formula for lost circulation control of oil-based drilling fluids in a $1 \times 0.5 \mathrm{~mm}$ slot.

\begin{tabular}{cccccccc}
\hline Testing Sample & SCC-II & RUB-II & SCC-III & RUB-III & SCC-IV & FIB & OAP \\
\hline No. 1 & $2.0 \%$ & $0.5 \%$ & $3.0 \%$ & $0.5 \%$ & $1.0 \%$ & $0.1 \%$ & - \\
No. 2 & $2.0 \%$ & $0.5 \%$ & $3.0 \%$ & $0.5 \%$ & $1.0 \%$ & $0.1 \%$ & $1.0 \%$ \\
\hline
\end{tabular}

The testing results shown in Figure 16 indicates that, for the control sample of formula No. 1, the fluid loss volume kept stable when the pressure less than 4.0 MPa, indicating the blended materials formed effective sealing in the fracture. After that, the fluid loss volume increased to $17 \mathrm{~mL}$ regardless of the increase of pressure. While for formula No. 2, the fluid loss volume was $5 \mathrm{~mL}$ at pressure of 1.0 MPa, then it increased to $7 \mathrm{~mL}$ and kept constant with the change of pressure, demonstrating that addition of OAP promoted formation of a tighter sealing in the fracture. As shown in Figure 17a, SCC particles and rubber particles were trapped with fibers to form a sealing integrity in the fracture. After OAP incorporation, as depicted in Figure 17b, SCC particles, rubber particles and OAP particles lodged against each other with the help of fibers binding. After rigid particles bridging, the resilient and deformable particles could fill in the formed voids, which was favorable for forming a tighter seal and lower fluid loss. 


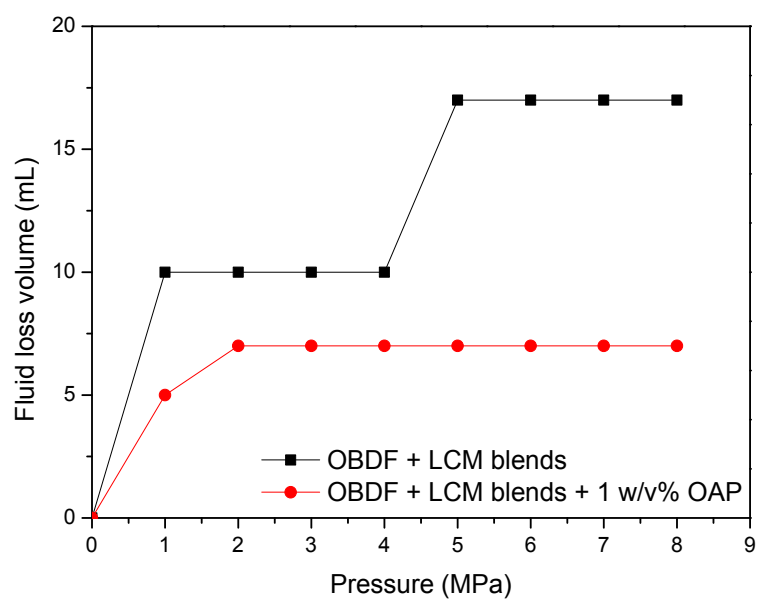

Figure 16. Performance of LCM blends and LCM blends combined with OAP to control the lost circulation in oil-based drilling fluids $(1 \times 0.5 \mathrm{~mm}$ slot $)$.
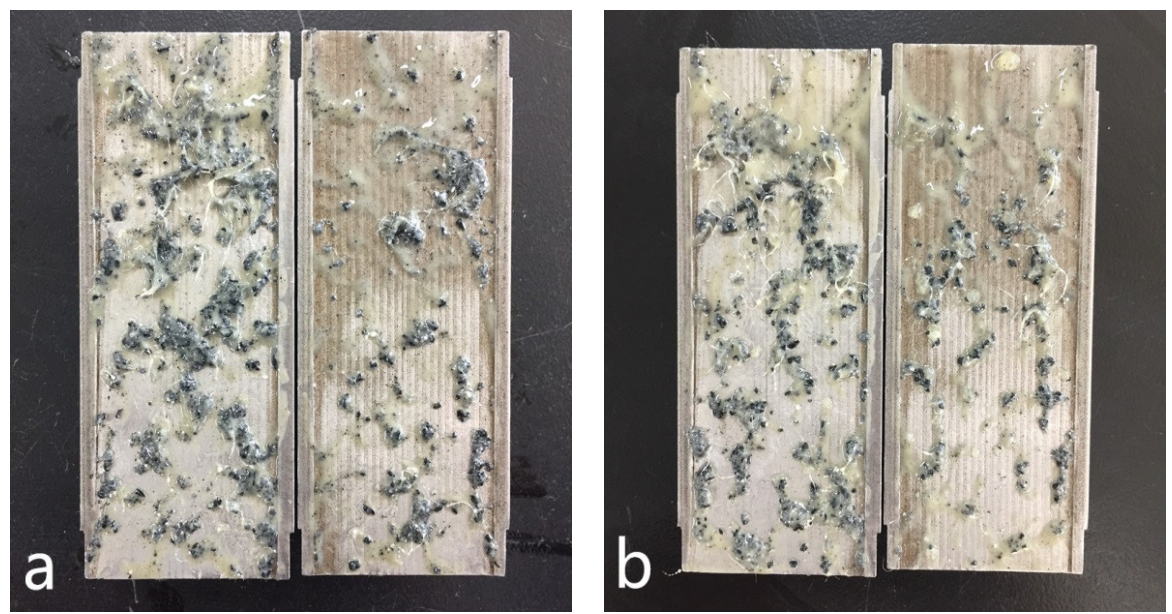

Figure 17. LCMs distribution in the slots after the fracture sealing test. Note: (a) formula No. 1; (b) formula No. 2.

(3) The sealing capacity of LCMs in a $2 \times 1 \mathrm{~mm}$ width slot.

This type of slot was used to simulate moderate to severe losses. To form effective sealing, the SCC particles, rubber particles and fibers with appropriate size distribution and concentration were optimized after extensive experiments, then the optimized formula No. 3 was established as control sample and shown in Table 8. The fracture sealing test results for OBDFs containing formulas No. 3 and No. 4 are given in Figure 18. It was clear that, for both formulas No. 3 and No. 4, a jump of fluid loss was observed at pressure of 2.0 MPa. For formula No. 3, the fluid loss increased to $40 \mathrm{~mL}$ at $2.0 \mathrm{MPa}$ and kept almost constant with the further increase of pressure. When the pressure reached $8.0 \mathrm{MPa}$, the fluid loss was $45 \mathrm{~mL}$. A similar phenomenon was observed for formula No. 4, where the fluid loss increased to $15 \mathrm{~mL}$ and kept unchanged regardless of the increase of pressure, again indicating that incorporation of OAP contributed to a denser sealing and lower fluid loss. As shown in Figure 19a, it was seemed that the blended LCMs without OAP were mainly distributed on the tail of the fracture, which was relatively easy to be extruded out of the fracture and led to failure of sealing. While in the presence of OAP, as observed in Figure 19b, the blended LCMs filled along the entire fracture, beneficial to forming a steady sealing. The results also verified that the addition of OAP improved the retention of LCMs in the fractures, which in turn caused lowered fluid loss. 
Table 8. LCM formula for lost circulation control of oil-based drilling fluids in a $2 \times 1 \mathrm{~mm}$ slot.

\begin{tabular}{ccccccccc}
\hline Testing Sample & SCC-I & SCC-II & RUB-II & SCC-III & RUB-III & SCC-IV & FIB & OAP \\
\hline No. 3 & $4.0 \%$ & $2.0 \%$ & $0.5 \%$ & $3.0 \%$ & $0.5 \%$ & $1.0 \%$ & $0.2 \%$ & - \\
No. 4 & $4.0 \%$ & $2.0 \%$ & $0.5 \%$ & $3.0 \%$ & $0.5 \%$ & $1.0 \%$ & $0.2 \%$ & $1.0 \%$ \\
\hline
\end{tabular}

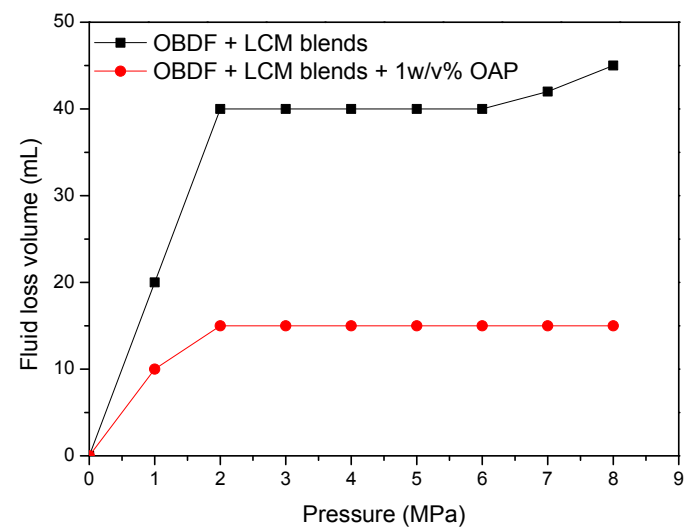

Figure 18. Performance of LCM blends and LCM blends combined with OAP to control the lost circulation in oil-based drilling fluids $(2 \times 1 \mathrm{~mm}$ slot $)$.
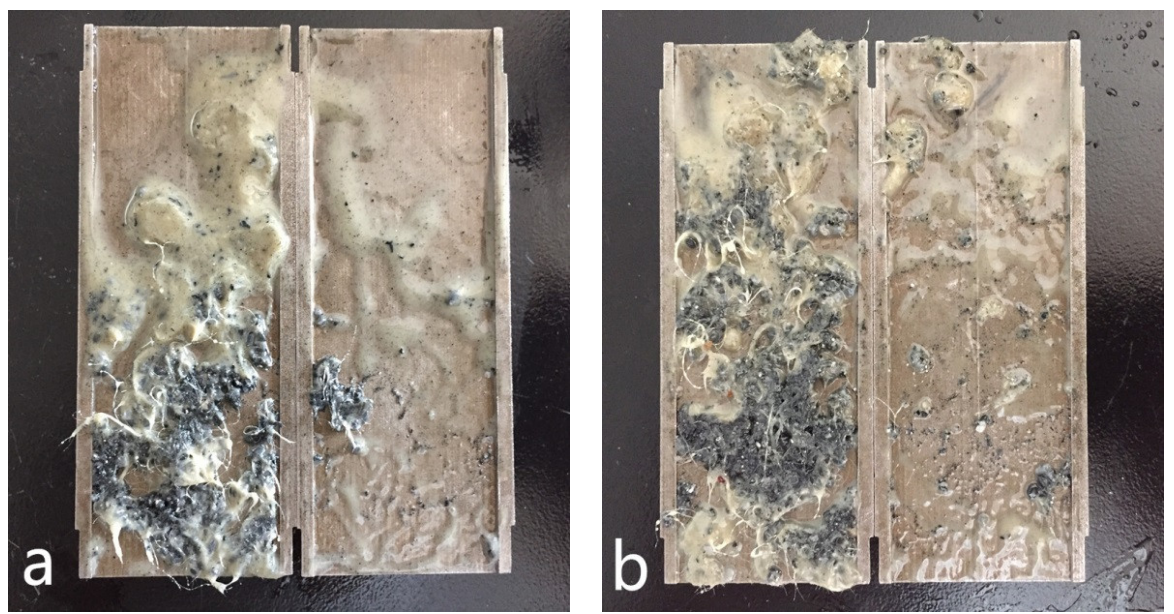

Figure 19. LCM distribution in the slots after the fracture sealing test. Note: (a) Formula No. 3, (b) Formula No. 4.

\subsection{Probable Mechanism of Mitigation of Lost Circulation}

OAP particles were synthesized by MMA, BA and LHA with typical crosslinked structure. The crosslinking chemicals tied the chains together to form a three-dimensional network, which enabled the polymers to absorb oil into the spaces in the molecular network and thus formed a gel that locks up the liquid. The oil-absorption process was an expansion process of this three-dimensional network, which had a clear transition from the high initial rate to the slow rate and toward the end of swelling equilibrium by the van der Waals attractive forces between molecules [54].

Because the oil absorption depended mainly on van der Waals attractive force, the oil absorption speed was relatively slow compared to that of water absorption resins; when pumped to downhole before absorption saturation, it would have a lower viscosity and small volume. Upon entering the lost-circulation zone, the absorption of oil continued, forming a viscous plug, and created a barrier to the subsequent flow of drilling fluid into the fracture channels. Meanwhile, after thorough adsorption under downhole conditions, the OAP particles swelled appreciably in volume and became resilient, which enabled them to be more effective in packing fractures even with smaller widths. However, 
due to their low compressive strength, the OAP particles were not efficient in closing off the lost circulation zone alone. When taking the rigid particles, elastic particles, fibers and OAP particles in combination by considering the particle shape, surface texture, concentration, particle size distribution and fracture width, a synergistic effect was obtained. The rigid SCC particles firstly formed bridging in the fracture, which was the framework of the sealing zone. The fibers that wrapped the mixture of other particles together improved the compactness of the sealing zone. After bridging in the fractures by rigid particles, deformable particles like OAP particles were able to occupy the voids among the previously bridged particles and reduce the permeability of the formed seal. Finally, a tight sealing zone was formed and resulted in a significant drop of fluid loss.

\section{Conclusions}

In this study, the oil-absorbent polymer (OAP) including MMA, SA, and BA was prepared by suspension polymerization. The OAPs had spherical and porous structure, and were capable of absorbing white oil and diesel oil several times of its own weight at temperatures ranging from room temperature to $120^{\circ} \mathrm{C}$.

The addition of OAP had relatively little influence on the rheological properties of OBDF at content lower than $1.5 \mathrm{w} / \mathrm{v} \%$ but increased the fluid viscosity remarkably at content higher than $3 w / v \%$. OAP particles could reduce the HTHP filtration and improve the sealing capacity of OBDFs effectively under downhole conditions. OAP particles used individually showed poor fracture-sealing capacity, but could effectively decrease fluid loss when treated conjunct with calcium carbonate particles, rubbers and fibers by a synergistic effect.

After addition of OAP into the OBDF, the volume of OAP would increase with time, which resulted in the increase of viscosity of the fluid and slowed down the fluid loss speed. Meanwhile, the swelled and deformable OAP could be compressed to enter an opening that is substantially smaller and different in shape. OAP particles would conform to the openings with various shapes and sizes. More importantly, OAP particles could occupy the voids of the bridging layer, and resulted in a tight sealing zone when used in combination with other conventional LCMs.

Author Contributions: Conceptualization, H.Z. and Z.Q.; Methodology, G.S., Investigation, X.X., Resources, P.Y.; Data Curation, H.Z. and G.S.; Writing-Original Draft Preparation, H.Z.; Funding Acquisition, J.J.

Funding: This work was financially supported by National Natural Science Foundation of China (No. 51704322, No. U1562101), Natural Science Foundation of Shandong Province (No. ZR2017QEE011), the 13th Five-year Plan National Key project (2017ZX05005005-006) and Program for Changjiang Scholars and Innovative Research Team in University (IRT_14R58) and the Fundamental Research Funds for the Central Universities (No. 18CX02099A).

Acknowledgments: The authors are grateful to Jiaxu Chen and Jia Li for their assistance in the preparing of fracture-sealing experiments.

Conflicts of Interest: There are no conflicts to declare.

\section{References}

1. Jeennakorn, M.; Nygaard, R.; Nes, O.M.; Saasen, A. Testing conditions make a difference when testing LCM. J. Nat. Gas Sci. Eng. 2018, 46, 375-386. [CrossRef]

2. Nasiri, A.; Shahrabi, M.A.; Moraveji, M.K. Application of new eco-friendly LCMs for combating the lost circulation in heavy-weight and oil-based mud. RSC Adv. 2018, 8, 9685-9696. [CrossRef]

3. Fidan, E.; Babadagli, T.; Kuru, E. Use of Cement as Lost Circulation Material-Field Case Studies. In Proceedings of the SPE-88005, IADC/SPE Asia Pacific Drilling Technology Conference and Exhibition, Kuala Lumpur, Malaysia, 13-15 September 2004.

4. Alshubbar, G.; Nygaard, R.; Jeennakorn, M. The effect of wellbore circulation on building an LCM bridge at the fracture aperture. J. Petrol. Sci. Eng. 2018, 165, 550-556. [CrossRef]

5. Savari, S.; Whitfill, D.L.; Kumar, A. Resilient lost circulation material (LCM): A significant factor in effective wellbore strengthening. In Proceedings of the SPE 153154, SPE Deepwater Drilling and Completions Conference, Galveston, TX, USA, 20-21 June 2012. 
6. Miller, M.L.; Scorsone, J.T.; Whitfill, D.L.; McDonald, M.; Miller, N. The development of a geopolymer-based pill as an engineered solution to lost circulation. In Proceedings of the SPE 166123, SPE Annual Technical Conference and Exhibition, New Orleans, LA, USA, 30 September-2 October 2013.

7. Moazzeni, A.R.; Nabaei, M.; Jegarluei, S.G. Prediction of lost circulation using virtual intelligence in one of Iranian oilfields. In Proceedings of the SPE 136992, Anuual International Conference and Exhibition, Calabar, Nigeria, 31 July-7 August 2010.

8. Alsaba, M.; Al Dushaishi, M.F.; Nygaard, R.; Nes, O.M.; Saasen, A. Updated criterion to select particle size distribution of lost circulation materials for an effective sealing. J. Petrol. Sci. Eng. 2017, 149, 641-648. [CrossRef]

9. Sanders, W.W.; Williamson, R.N.; Ivan, C.D.; Powell, D. Lost circulation assessment and planning program: Evolving strategy to control severe losses in deepwater projects. In Proceedings of the SPE 79836, SPE/IADC Drilling Conference, Amsterdam, The Netherlands, 19-21 February 2003.

10. Arshad, U.; Jain, B.; Ramzan, M.; Alward, W.; Diaz, L.; Hasan, I.; Aliyev, A.; Chen, R. Engineered solution to reduce the impact of lost circulation during drilling and cementing in Rumaila Field, Iraq. In Proceedings of the IPTC 18245, International Petroleum Technology Conference, Doha, Qatar, 6-9 December 2015.

11. Alkinani, H.H.; Al-Hameedi, A.T.; Flori, R.E.; Dunn-Norman, S.; Hilgedick, S.A.; Alsaba, M.T. Updated classification of lost circulation treatments and materials with an integrated analysis and their applications. In Proceedings of the SPE 190118, SPE Western Regional Meeting, Garden Grove, CA, USA, 22-26 April 2018.

12. Sanders, M.W.; Young, S.; Friedheim, J. Development and testing of novel additives for improved wellbore stability and reduced losses. In Proceedings of the AADE-08-DF-HO-19, AADE Fluids Conference and Exhibition, Houston, TX, USA, 8-9 April 2008.

13. White, R.J. Lost-circulation materials and their evaluation. In Drilling and Production Practice; American Petroleum Institute: New York, NY, USA, 1956.

14. Boukadi, F.; Yaghi, B.; Al-Hadrami, H.; Bemani, A.; Babadagli, T.; Mestre, P.D. A comparison study of lost circulation materials. Energy Source 2004, 26, 1043-4051. [CrossRef]

15. Nasiri, A.; Ghaffarkhah, A.; Moraveji, M.K.; Gharbanian, A.; Valizadehd, M. Experimental and field test analysis of different loss control materials for combating lost circulation in bentonite mud. J. Nat. Gas Sci. Eng. 2017, 44, 1-8. [CrossRef]

16. Luzardo, J.; Oliveira, E.P.; Derks, P.W.J.; Vega Nascimento, R.; Perez Gramatges, A.; Valle, R.; Gianoglio Pantano, I.; Sbaglia, F. Alternative lost circulation material for depleted reservoirs. In Proceedings of the OTC 26188, Offshore Technology Conference, Rio de Janeiro, Brazil, 27-29 October 2015.

17. Al-saba, M.T.; Nygaard, R.; Saasen, A.; Nes, O.-M. Laboratory evaluation of sealing wide fractures using conventional lost circulation materials. In Proceedings of the SPE 170576, SPE Annual Technical Conference and Exhibition, Amsterdam, The Netherlands, 27-29 October 2014.

18. Soares, A.S.F.; Marques, M.R.C.; Calçada, L.A.; Filho, M.N.B.; de Oliveira Petkowicz, C.L. Interaction of blockers on drilling fluids rheology and its effects on sealing of fractures and prevention of filtration invasion. J. Petrol. Sci. Eng. 2018, 171, 260-270. [CrossRef]

19. Wang, H. Is it really possible to efficiently form a strong seal inside subterranean openings without knowing their shape and size? In Proceedings of the AADE-11-NTCE-25, AADE National Technical Conference and Exhibition, Houston, Texas, USA, 12-14 April 2011.

20. Mansour, A.K.; Taleghani, A.D. Smart loss circulation materials for drilling highly fractures zones. In Proceedings of the SPE 189413, SPE/IADC Middle Drilling Technology Conference and Exhibition, Abu Dhabi, UAE, 29-31 January 2018.

21. Savari, S.; Whitfill, D.L.; Jamison, D.E. A method to evaluate lost circulation materials-investigation of effective wellbore strengthening applications. In Proceedings of the SPE 167977, IADC/SPE Drilling Conference and Exhibition, Fort Worth, TX, USA, 4-6 March 2014.

22. Mas, M.; Tapin, T.; Márquez, R.; Gabay, R.; Negrín, Z.; Díaz, C.; Bejarano, L. A new high-temperature oil-based drilling fluid. In Proceedings of the SPE 53941, Latin American and Caribbean Petroleum Engineering Conference, Caracas, Venezuela, 21-23 April 1999.

23. Aragao, A.F.L.; Quintero, L.; Martins, A.L.; Calderon, A.; Sa, A.; Mckellar, A.; Gabrysch, A.D. A novel approach for drilling and gravel packing horizontal wells in the presence of reactive shales using a solids-free synthetic fluid. In Proceedings of the SPE 102295, SPE Annual Technical Conference and Exhibition, San Antonio, TX, USA, 24-27 September 2006. 
24. Dias, F.T.G.; Souza, R.R.; Lucas, E.F. Influence of modified starches composition on their performance as fluid loss additives in invert-emulsion drilling fluids. Fuel 2015, 140, 711-716. [CrossRef]

25. Delhommer, H.J.; Walker, C.O. Encapsulated Oil Absorbent Polymers as Lost Circulation Additives for Oil Based Drilling Fluids. U.S. Patent 4704213, 3 November 1987.

26. Power, D.; Ivan, C.D.; Brooks, S.W. The top 10 lost circulation concerns in deepwater drilling. In Proceedings of the SPE 81133, SPE Latin American and Caribbean Petroleum Engineering Conference, Port-of-Spain, Trinidad and Tobago, 27-30 April 2003.

27. Onyia, E.C. An analysis of experimental data on lost circulation problems while drilling with oil-base mud. In Proceedings of the SPE 22581, SPE Annual Technical Conference and Exhibition, Dallas, TX, USA, 6-9 October 1991.

28. Feng, Y.; Gray, K.E. Review of fundamental studies on lost circulation and wellbore strengthening. J. Petrol. Sci. Eng. 2017, 152, 511-522. [CrossRef]

29. He, W.; Jimbi, E.; Chamberlin, M.; Zakaria, A. Invasion and movement of fluids in shale formations and wellbore stability. In Proceedings of the SPE 178766, IADC/SPE Drilling Conference and Exhibition, Fort Worth, TX, USA 1-3 March 2016.

30. Yan, X.; You, L.; Kang, Y.; Li, X.; Xu, C.; She, J. Impact of drilling fluids on friction coefficient of brittle gas shale. Int. J. Rock Mech. Min. 2018, 106, 144-152. [CrossRef]

31. Aadnoy, B.S.; Belayneh, M.; Jorquera, M.A.A.; Flateboe, R. Design of well barriers to combat circulation losses. SPE Drill. Complet. 2008, 23, 295-300. [CrossRef]

32. Hoskins, T.W. Drilling Fluid Additive for Reducing Lost Circulation in a Drilling Operation. U.S. Patent 8607895, 17 December 2013.

33. Suyan, K.M.; Sharma, V.; Jain, V.K. An innovative material for severe lost circulation control in depleted formations. In Proceedings of the SPE 125693, SPE/IADC Middle East Drilling Technology Conference \& Exhibition, Manama, Bahrain, 26-28 October 2009.

34. Growcock, F.B.; Patel, A.D. The revolution in non-aqueous drilling fluids. In Proceedings of the AADE-11 -NTCE-33, AADE National Technical Conference and Exhibition, Houston, TX, USA, 12-14 April 2011.

35. Lai, X.; Guo, J.; Zhou, Y.; Jiang, X.; Li, X.; Wang, Z. A new water-absorbent resin for lost circulation control. In Proceedings of the SPE 131605, International Oil \& Gas Conference and Exhibition, Beijing, China, 8-10 June 2010.

36. Walker, C.O. Method for Controlling Lost Circulation of Drilling Fluids with Water Absorbent Polymers. U.S. Patent 4635726, 13 January 1987.

37. Whitfill, D.L.; Hemphill, T. All lost-circulation materials and systems are not created equal. In Proceedings of the SPE 84319, SPE Annual Technical Conference and Exhibition, Denver, CO, USA, 5-8 October 2003.

38. Liang, Y.; Wang, D.; Chen, H. Preparation of high oil absorption resins by suspended emulsion polymerization and their properties. Sep. Sci. Technol. 2013, 48, 1977-1981. [CrossRef]

39. Ji, N.; Chen, H.; Yu, M.; Qu, R.; Wang, C. Synthesis of high oil-absorption resins of poly(methyl methacrylate-butyl methacrylate) by suspended emulsion polymerization. Polym. Adv. Technol. 2011, 22, 1898-1904. [CrossRef]

40. Huang, X.; Jiang, G.; He, Y.; An, Y.; Zhang, S. Improvement of rheological properties of invert drilling fluids by enhancing interactions of water droplets using hydrogen bonding linker. Colloid Surf. A 2016, 506, 467-475. [CrossRef]

41. Huo, J.H.; Peng, Z.G.; Ye, Z.; Feng, Q.; Zheng, Y.; Zhang, J.; Liu, X. Investigation of synthesized polymer on the rheological and filtration performance of water-based drilling fluid system. J. Petrol. Sci. Eng. 2018, 165, 655-663. [CrossRef]

42. Santos, H.; Villas-Boas, M.B.; Lomba, R.F.T.; Sá, C.H.M.; Oliveira, S.F.; Costa, J.F. API filtrate and drilling fluid invasion: Is there any correlation? In Proceedings of the SPE 53791, SPE Latin American and Caribbean Petroleum Engineering Conference, Caracas, Venezuela, 21-23 April 1999.

43. Moroni, L.P.; Vickers, S.; Gray, C.; Davidson, M. Good things come in little packages: Nanotechnoloty for reduction in pore pressure transmission. In Proceedings of the SPE 170687, SPE Annual Technical Conference and Exhibition, Amsterdam, The Netherland, 27-29 October 2014.

44. Nayberg, T.M.; Petty, B.R. Laboratory study of lost circulation materials for use in oil-base drilling muds. In Proceedings of the SPE 14995, SPE Deep Drilling and Production Symposium, Society of Petroleum Engineers, Amarillo, TX, USA, 6-8 April 1986. 
45. Abdulrazzaq, W.; Alburaikan, R.; Savari, S.; Whitfill, D.L. New methodology to evaluate the performance of chemical sealant loss circulation materials. In Proceedings of the SPE 187598, SPE Kuwait Oil \& Gas Show and Conference, Kuwait City, Kuwait, 15-18 October 2017.

46. Zhong, H.; Qiu, Z.; Chai, J.; Guo, B.; Sun, D.; Liu, J. A preliminary study of the preparation of shale stabilizer with oil sludge- from waste to resource. J. Petrol. Sci. Eng. 2018, 161, 50-60. [CrossRef]

47. Ren, J.; Liao, R.; Wang, W.; Li, Y.; Gao, J. Synthesis and characterization of a highly absorptive resin using glow discharge electrolysis plasma. Int. J. Ind. Chem. 2013, 4, 1-6. [CrossRef]

48. Niu, S. Study on the Newly Drilling Fluid Technology for Lost Circulation Prevention and Control. Master's Thesis, China University of Petroleum, Beijing, China, 1 July 2007. (In Chinese)

49. Balavi, H.; Boluk, Y. Dynamic filtration of drilling fluids and fluid loss under axially rotating crossflow filtration. J. Petrol. Sci. Eng. 2018, 163, 611-615. [CrossRef]

50. Clark, P.E.; Barkat, O. Analysis of fluid-loss data. SPE Prod. Eng. 1990, 5, 306-310. [CrossRef]

51. Roodhard, L.P. Fracturing fluids: Fluid-loss measurements under dynamic conditions. SPE J. 1985, 25, $629-636$. [CrossRef]

52. Savari, S.; Whitfill, D.L. Lost circulation management in naturally fractured formations: Efficient operational strategies and novel solutions. In Proceedings of the SPE 178803, IADC/SPE Drilling Conference and Exhibition, Fort Worth, TX, USA, 1-3 March 2016.

53. Abrams, A. Mud design to minimize rock impairment due to particle invasion. J. Pet. Technol. 1977, $29,586-592$. [CrossRef]

54. Shan, G.R.; Xu, P.Y.; Weng, Z.X.; Huang, Z.M. Synthesis and properties of oil absorption resins filled with polybutadiene. J. Appl. Polym. Sci. 2003, 89, 3309-3314. [CrossRef]

(C) 2018 by the authors. Licensee MDPI, Basel, Switzerland. This article is an open access article distributed under the terms and conditions of the Creative Commons Attribution (CC BY) license (http:/ / creativecommons.org/licenses/by/4.0/). 